\title{
WEIGHTING METHODS IN CONSTRUCTION OF ACTIVE AGEING INDICATOR
}

\author{
ALENA KAŠČÁKOVÁ, VIERA MENDELOVÁ, GABRIELA NEDELOVÁ \\ Matej Bel University in Banská Bystrica, Faculty of Economics, \\ Department of Quantitative Methods and Information Systems, \\ Tajovského 10, 97590 Banská Bystrica, Slovakia \\ email: alena.kascakova@umb.sk, viera.mendelova@umb.sk,gabriela.nedelova@umb.sk
}

\begin{abstract}
A newly developed tool to measure and promote the potential of the older population in EU countries is the Active Ageing Index (AAI). The index measures the active ageing performance across twenty indicators in four distinct domains with respect to employment, healthy, independent and autonomous living, and to make other unpaid family, social and cultural contributions to the society in a given country. For the construction of aggregation indices in years 2010, 2012 and 2014 one easy aggregation method based on the recommendation of the Expert group was used. The aim of this contribution is to show the differences in active ageing performance of European countries based on AAI when different methods for weights determination and different multi-criteria methods for ranking countries are used. The results of using the different weighting methods for aggregation of indicators and domains are compared and the recommendation for ranking countries is given.
\end{abstract}

Key words: active aging indicator

JEL Codes: J14

DOI: 10.15611/amse.2017.20.20

\section{Introduction}

One of the most typical demographic processes in Europe is population ageing. As a result, the proportion of people of working age is shrinking while the relative number of those retired is expanding. In almost every country, the proportion of people aged over 60 years is growing faster than any other age group, as a result of both longer life expectancy and declining fertility rates.

Older people do not want only to live longer, but also to achieve healthy and active ageing including doing regular physical activity, actively participate socially and engage with others, have access to healthcare, security and lifelong learning.

On May 26, 2016, member states adopted the Global Strategy and Action Plan on Ageing and Health 2016-2020 at the 69th World Health Assembly. The Strategy outlines a set of goals and strategic objectives to move towards a decade of Healthy Ageing beginning in 2020, and an action plan to achieve those goals.

Active ageing is defined as "the process of optimizing opportunities for health, participation and security in order to enhance quality of life as people age" (WHO, 2002, p. 12). "Active ageing applies to both individuals and population groups. It allows people to realize their potential for physical, social, and mental well-being throughout the life course and to participate in society according to their needs, desires and capacities, while providing them with adequate protection, security and care when they require assistance" (WHO, 2002, p. 12). For measuring the level of older people's participation in the labour market and in the 
social and family activities in European countries was constructed the Active Ageing Index (Zaidi, 2017).

\section{Active Ageing Index}

The Active Ageing Index ( $A A I)$ is a tool to monitor active ageing outcomes at the country level and to describe the untapped potential of older people to participate actively in economic and social life, with the objective of promoting an active role for older people. The $A A I$ is a composite measure, obtained by aggregating scores from four domains: (a) employment, (b) participation in society, (c) independent, healthy and secure living, and (d) enabling environment. Measures in the area of employment aim at creating better opportunities and employability for older workers; measures in the area of participation are to be focused on combating the social exclusion of older people by fostering their active participation in the society (by encouraging voluntary activities and support for informal carers); measures in the area of independent living should encourage healthy ageing and independent self-reliant living by emphasizing a preventive approach in health and social care, making transport more accessible, and making the environment more age friendly (Sidorenko, Zaidi, 2012). 22 individual indicators are drawn using mainly four major European household surveys. They are: EU Labour Force Survey, EU Survey on Income and Living Conditions. European Quality of Life Survey, European Social Survey. Indicators for life expectancy and healthy life expectancy are provided by EU project European health and Life Expectancy Information system. Data for indicator "Use of ICT" was collected by Eurostat's ICT Survey.

\section{Research Methodology}

It is very difficult to evaluate the active ageing performance (AAP) on the ground of too many indicators. The evaluation of the AAP becomes a problem of multiple-criteria decision analysis (MCDA). The main purpose of the methodology for the $A A I$ construction is to reduce the number of indicators by aggregating them into four sub-indices (Employment subindex $-I^{\mathrm{E}}$, Participation in society sub-index $-I^{\mathrm{P}}$, Independent and secure living subindex $-I^{\mathrm{L}}$ and Capacity and enabling environment for active ageing $-I^{\mathrm{C}}$ ) for each distinct domain of active ageing performance. The sub-indices are than combined into the composite active ageing index $(A A I)$. Figure 1 shows the basic hierarchy of composing indicators into the $A A I$.

Figure 1: Generic hierarchy scheme for construction of composite strategic performance index

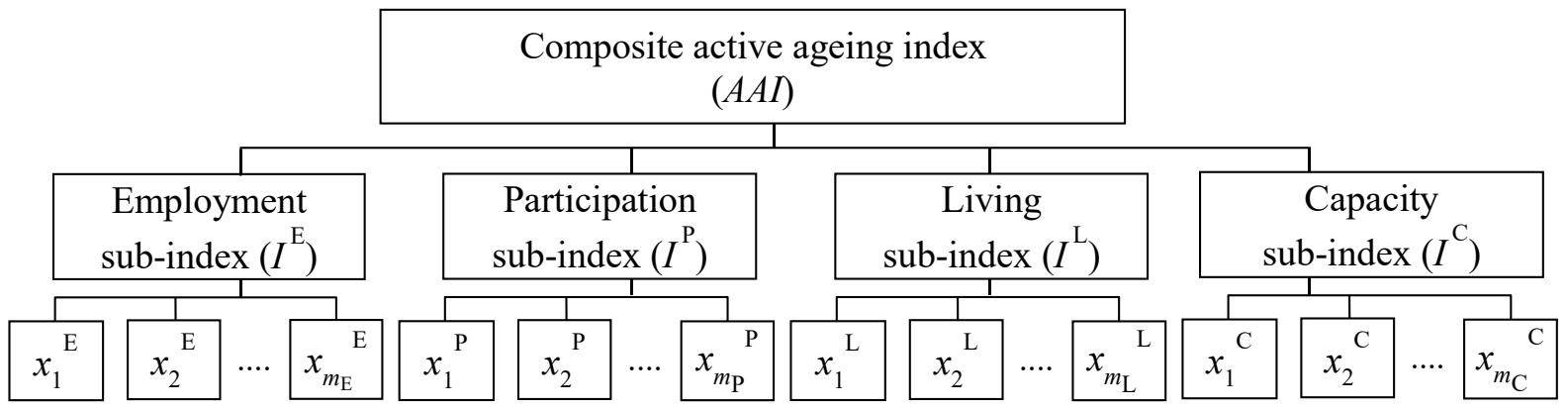

Source: the authors. 


\subsection{Defining the indicators for each domain of the AAP}

At first, for each European country $i, i=1, \ldots, n$ the indicators in the employment domain (E), participation in society domain $(\mathrm{P})$, independent and secure living domain $(\mathrm{L})$, and capacity and enabling environment for active ageing domain (C) are selected (see Table 1).

Table 1: Indicators considered in each domain of the active ageing performance

\begin{tabular}{|c|c|c|}
\hline Domain & Indicator & Definition \\
\hline $\mathrm{E}$ & $\begin{array}{l}\text { - Employment rate 55-59 } \\
\text { - Employment rate 60-64 } \\
\text { - Employment rate 65-69 } \\
\text { - Employment rate 70-74 }\end{array}$ & $\begin{array}{l}\text { - is the percentage of employed persons of the age 55-59 in } \\
\text { relation to the total population aged 55-59 } \\
\text { - is the percentage of employed persons of the age } 60-64 \text { in } \\
\text { relation to the total population aged } 60-64 \\
\text { - is the percentage of employed persons of the age } 65-69 \text { in } \\
\text { relation to the total population aged } 65-69 \\
\text { - is the percentage of employed persons of the age } 70-74 \text { in } \\
\text { relation to the total population aged } 70-74\end{array}$ \\
\hline $\mathrm{P}$ & $\begin{array}{l}\text { - Voluntary activities } \\
\text { - Care to children, grandchildren } \\
\text { - Care to older adults } \\
\text { - Political participation }\end{array}$ & $\begin{array}{l}\text { - Percentage of older population (aged 55+) providing unpaid } \\
\text { voluntary work through the organizations (at least once a week) } \\
\text { - Percentage of older population (aged 55+) who provide care to } \\
\text { their children and grandchildren (at least once a week) } \\
\text { - Percentage of older population (aged 55+) providing personal } \\
\text { care to elderly or disabled relatives (at least once a week) } \\
\text { - Percentage of older population (aged 55+) taking part in the } \\
\text { activities or meetings of a trade union, political party or political } \\
\text { action group, or signing petitions, including email and online } \\
\text { ones }\end{array}$ \\
\hline $\mathrm{L}$ & $\begin{array}{l}\text { - Physical exercise } \\
\text { - No unmet needs of health and } \\
\text { dental care } \\
\text { - Independent living arrangements } \\
\text { - Relative median income }\end{array}$ & $\begin{array}{l}\text { - Percentage of people aged } 55 \text { years and older undertaking } \\
\text { physical exercise or sport almost every day } \\
\text { - Percentage of people aged } 55 \text { years and older who report no } \\
\text { unmet need for medical and dental examination or treatment } \\
\text { during the last } 12 \text { months preceding the survey } \\
\text { - Percentage of people aged } 75 \text { years and older who live in a single } \\
\text { household alone or in a couple household } \\
\text { - Ratio of the median equivalised disposable income of people } \\
\text { aged } 65 \text { and above to the median equivalised disposable income } \\
\text { of those aged below } 65 \\
\text { - } 100 \text { - Percentage of people aged } 65 \text { years and older who are at } \\
\text { risk of poverty (using the } 50 \text { per cent of median income } \\
\text { threshold) } \\
\text { - } 100 \text { - Percentage of people aged } 65 \text { years and older who are } \\
\text { severely materially deprived (having an enforced inability to } \\
\text { afford at least } 4 \text { out of the } 9 \text { selected items) } \\
\text { - Percentage of people aged } 55 \text { years and older who are feeling } \\
\text { very safe or safe to walk after dark in their local area } \\
\text { - Percentage of people aged } 55 \text { to } 74 \text { who stated that they received } \\
\text { education or training in the four weeks preceding the survey }\end{array}$ \\
\hline $\mathrm{C}$ & $\begin{array}{l}\text { - RLE achievement of } 50 \text { years at } \\
\text { age } 55 \\
\text { - Share of healthy life years in the } \\
\text { RLE at age } 55 \\
\text { - Mental well-being } \\
\text { - Use of ICT } \\
\text { - Social connectedness } \\
\text { - Educational attainment }\end{array}$ & $\begin{array}{l}\text { - Remaining life expectancy at age } 55 \text { as a proportion of } 50 \text { years } \\
\text { goalpost (RLE at } 55 \text { divided by } 50 \text { to calculate the proportion of } \\
\text { life expectancy achievement in the target of } 105 \text { years of life } \\
\text { expectancy) } \\
\text { - Share of healthy life years in the remaining life expectancy at age } \\
55 \\
\text { - An index that measures self-reported feelings of positive happy } \\
\text { moods and spirits } \\
\text { - Share of people aged } 55 \text { to } 74 \text { using the Internet at least once a } \\
\text { week } \\
\text { - Share of people aged } 55 \text { or more that meet socially with friends, } \\
\text { relatives or colleagues at least once a week } \\
\text { - Percentage of older persons aged } 55 \text { to } 74 \text { with upper secondary } \\
\text { or tertiary educational attainment }\end{array}$ \\
\hline
\end{tabular}

Source: AAI in brief, 2012. 
It is important to emphasize that for each domain of the AAP, the indicators considered have a positive impact on the AAP, i.e. their higher value represents higher performance.

\subsection{Methods for weights determination}

The crucial procedural part of the $A A I$ construction involves determining weights to individual indicators. In each domain $k, k=\mathrm{E}, \mathrm{P}, \mathrm{L}, \mathrm{C}$ we consider $m_{k}$ indicators. Weights for indicators $\left(w_{j}^{k}, j=1, \ldots, m_{k}\right)$ are the numerical expression of their significance in the domain $k$. The greater the weight of a certain indicator, the more important this indicator is in overall evaluation. The weights of the individual indicators are usually normalized so that their sum in each domain $k$ is equal to 1 , i.e. $\sum_{j=1}^{m_{k}} w_{j}^{k}=1$. Numerous approaches have been proposed to determine weights in MCDA models. They can be in general classified into two main groups, objective and subjective methods (Tzeng et al., 1998). The subjective methods determine the weights based on expert evaluation, the objective methods determine the weights through mathematical calculation using objective information in a decision matrix. In this paper, only subjective methods are under spotlight. The subjective methods considered in this paper include (1) the rank order method (see e.g. Ahn and Park, 2008), (2) the direct rating method (see e.g. Bottomley and Doyle, 2001), (3) the pairwise comparison method and (4) the analytic hierarchy process of Saaty (1980).

The rank order $(R O)$ method:

The RO method is simple way of calculating weights for a number of indicators. A decision-maker should first rank a set of $m_{k}$ indicators in each domain $k, k=\mathrm{E}, \mathrm{P}, \mathrm{L}, \mathrm{C}$ according to their importance giving each indicator $j$ a rank $r_{j}^{k},\left(r_{j}^{k}=1, \ldots, m_{k}\right)$. The ranks are inversely related to the weights, i.e. the least important indicator will be given a rank of 1 and the most important indicator will be given a rank of $m_{k}$. The next step is giving normalized weight to each indicator based on its rank. The formula producing the normalized weights is the following:

$$
w_{j}^{k}=\frac{r_{j}^{k}}{\sum_{j=1}^{m_{k}} r_{j}^{k}},
$$

where $r_{j}^{k}$ is the rank of the indicator $j$ in the domain $k, j=1, \ldots, m_{k}$.

The direct rating (DR) method:

The DR method asked decision-maker to rate each indicator on a scale of $0-10$ according to its relative significance giving each indicator $j$ a rating $r_{j}^{k},\left(r_{j}^{k} \in[0,10]\right)$. The normalized weights are produced using the same formula (1) as in the previous RO method.

The pairwise comparison (PC) method:

In the PC method, known also as Fuller's triangle, the decision-maker has to deal with the triangle scheme in which the couple of the individual indicators are expressed. From each couple decision-maker has to pick one which is more important than the other one. This pairwise comparison assigns preferences to individual indicators. In the case when two indicators have the same importance, half the preference is assigned to each one. If the number of the preferences for the indicator $j$ in the domain $k$ is $p_{j}^{k}$, and $p_{j}^{k} \neq 0$ for all $m_{k}$ indicators, the normalized weights can be calculated using the formula: 


$$
w_{j}^{k}=\frac{p_{j}^{k}}{\sum_{j=1}^{m_{k}} p_{j}^{k}}
$$

and when $p_{j}^{k}=0$ for some indicator $j$, the normalized weights can be calculated using the formula:

$$
w_{j}^{k}=\frac{p_{j}^{k}+1}{m_{k}+\sum_{j=1}^{m_{k}} p_{j}^{k}}
$$

The analytic hierarchy process (AHP) method:

The AHP method of Saaty (1980) consists of pairwise comparisons of indicators with a view to obtaining the order of importance of each indicator. The comparisons need to be made between each pair of indicators in a given domain $k$. The intensity of preference of one indicator over the other is expressed on a factor scale from 1 to 9 (see Saaty, 1980). The results of pairwise comparisons are gradually written into the Saaty matrix $\mathbf{S}^{k}=\left(s_{i j}^{k}\right)_{m_{k} \times m_{k}}$, where the matrix element $s_{i j}^{k}$ expresses how many times the indicator $i$ is more important than the indicator $j$. That means there are only " 1 's" down the main diagonal of $\mathbf{S}^{k}$ and the following relation holds $s_{i j}^{k}=1 / s_{j i}^{k}$, i.e. all elements are reciprocal value of symmetric elements according to the diagonal. To check the consistency of each judgment, for each domain $k$, the consistency of the Saaty matrix $\mathbf{S}^{k}$ needs to be verified by the consistency index $C I_{k}$ in the form (3):

$$
C I_{k}=\frac{\lambda_{k}^{\max }-m_{k}}{m_{k}-1}
$$

where $\lambda_{k}^{\max }$ is the largest eigenvalue of the matrix $\mathbf{S}^{k}$. A value of $C I_{k}$ equals to 0.1 is considered as the acceptable upper limit. If $C I_{k}$ is greater than 0.1 then the re-evaluation of some judgments in $\mathbf{S}^{k}$ are needed. In the final step, the normalized weights are found using the following nonlinear optimization task:

$$
\min \sum_{i=1}^{m_{k}} \sum_{j=1}^{m_{k}}\left(s_{i j}^{k}-\frac{w_{i}^{k}}{w_{j}^{k}}\right)^{2} \quad \begin{aligned}
w_{1}^{k}, \ldots, w_{m_{k}}^{k} & >0, \\
w_{1}^{k}+\ldots+w_{m_{k}}^{k} & =1 .
\end{aligned}
$$

In the construction of the Saaty matrix in each domain, we proceeded from experts' indicator weights while the higher weight meant the higher importance of the indicator. The priority of original indicators and domains given by experts' were respected. Constructed matrix satisfied the condition of consistency $\left(C I_{1}=0 ; C I_{2}=0,015 ; C I_{3}=0 ; C I_{4}=1,91 \cdot 10^{-8}\right)$.

\subsection{Multi-criteria methods for ranking of countries}

There is a relatively wide range of MCDA methods that can be applied to aggregate multiple indicators into one composite indicator. The best known method used for the subindices construction is weighted sum (WS) model that is the simplest MCDA method for evaluating a number of alternatives in terms of a number of indicators. It is crucial to state 
here that the WS method is applicable only when all the data are expressed in exactly the same unit of measurement. However, this fundamental requirement is not met in real conditions of some problem studied. Even in the case when all indicators are expressed in the same units of measurement, as it is obvious also in our analysis where all indicators are expressed in the percentage, the different indicators value level can markedly distort the informative value of the composite sub-index. For example, if some object is the worst in all indicators except one which values are considerably higher than values of other indicators, and in this indicator a given object is considered as the best, the resulting WS consistency index for this object can be even the highest, i.e. the best from all other objects. This is the main shortcoming of this methodology.

One way to solve this problem is normalizing indicators using the appropriate MCDA methods that are based on the standardized data. In this paper we use two MCDA methods: the WS method and the Euclidean distance from ideal object method.

\subsubsection{The WS method}

The WS method will not be applied to the original data, but we use three different standardization techniques to eliminate the above-mentioned drawbacks of traditional WS method. The standardization techniques considered in this paper include (1) the rank order standardization, (2) the scoring standardization and (3) the normalization.

The rank order standardization:

The rank order standardization is the simplest method leading to the standardized data. We sort the countries in the sample by each indicator considered. The country that achieves the best, i.e. the highest value for the given indicator gets the order equal to the number of countries in the set $(n)$, the country with the second highest value gets the order $(n-1)$, etc. Using this procedure, each country $i, i=1, \ldots, n$ will get a rank $u_{i j}^{(1) k},\left(u_{i j}^{(1) k}=1, \ldots, n\right)$ according to each indicator $j$ in each domain $k$.

\section{The scoring standardization:}

One of the other standardization methods is to assign scores to individual countries according to the obtained indicator values in the following way:

$$
u_{i j}^{(2) k}=\frac{x_{i j}^{k}-x_{j \min }^{k}}{x_{j \max }^{k}-x_{j \min }^{k}},
$$

where $u_{i j}^{(2) k}$ is the normalized value of the indicator $j$ in the domain $k$ for the country $i, x_{i j}^{k}$ is the actual value of the indicator $j$ in the domain $k$ for the country $i, x_{j \text { min }}^{k}$ is the minimum value and $x_{j \max }^{k}$ is the maximum value of the indicator $j$ in the domain $k$. The equations (6) ensures that a normalized indicator $u_{i j}^{(2) k}$ will take values from $[0,1]$.

\section{The normalization:}

Third option for standardization data is to normalized indicators in a conventional way:

$$
u_{i j}^{(3) k}=\frac{x_{i j}^{k}-\bar{x}_{j}^{k}}{s d\left(x_{j}^{k}\right)},
$$


where $u_{i j}^{(3) k}$ is the normalized value of the indicator $j$ in the domain $k$ for the country $i, \bar{x}_{j}^{k}$ is the average value of the indicator $j$ in the domain $k$ and $s d\left(x_{j}^{k}\right)$ is the standard deviation of the indicator $j$ in the domain $k$.

With using the weights of indicators $\left(w_{j}^{k}\right)$ and standardized values of indicators $u_{i j}^{() k}$, the composite indicator integrating the relevant indicators in each domain $k$ can be derived as a weighted sum of the individual standardized indicators for each country $i$ as follows:

$$
I_{i}^{k}=\sum_{j=1}^{m_{k}} w_{j}^{k} \cdot u_{i j}^{() k},
$$

where $I_{i}^{k}$ represents the composite indicator for the country $i, i=1, \ldots, n$ in the domain $k, k=\mathrm{E}, \mathrm{P}, \mathrm{L}, \mathrm{C}$.

\subsubsection{The Euclidean distance from ideal object method}

This method uses the normalized values of indicators according to the relation (6) similar to the WS method. The main difference compared to the previously stated WS method is that this method does not create sub-indices as a linear combination of normalized values, but individual sub-indices represent the weighted average distance of individual countries from the ideal object. The Euclidean distance of the country $i$ form the ideal object is computed in the following way:

$$
I_{i}^{k}=\sqrt{\sum_{j=1}^{m_{k}}\left(\left(u_{i j}^{(3) k}-u_{\max j}^{(3) k}\right)^{2} \cdot w_{j}^{k}\right)},
$$

where $u_{i j}^{(3) k}$ is the normalized (according to relation (6)) value of the indicator $j$ in the domain $k$ for the country $i$ and $u_{\max j}^{(3) k}$ is the maximum value of the normalized (according to relation (6)) indicator $j$ in the domain $k$.

On the basis of value $I_{i}^{k}$ the rank of country in the domain $k$ is given.

\subsection{Calculation of the AAI and ranking of countries}

Finally, four sub-indices are combined into the composite index $A A I_{i}$ as follows:

$$
A A I_{i}=\frac{\sum_{k=1}^{4} W^{k} \cdot I_{i}^{k}}{\sum_{k=1}^{4} W^{k}},
$$

where $W^{k}$ denotes the factor representing a priori weight given to the domain $k ; \sum_{k=1}^{4} W^{k}=1$. It holds the higher value of the given index, the better position of a given country in comparison with other countries under analysis. The weights $W^{j}$ should reflect the relative importance given to the employment domain (E), participation in society domain (P), independent and secure living domain (L), and capacity and enabling environment for active ageing domain (C). For this purpose, an expert estimation or some method for the weight determination (e.g. already used RO, DR, PC or AHP method) can be used. The rank of 
country in the domain is assigned according to value of individual domain indices as well as according to the value of overall $A A I$.

\section{Results}

The data were collected for the construction of indicators mentioned in 3.1. and for the construction the $A A I$ in line with Concept, methodology and final results of the project Active Ageing Index, UNECE grant No: ECE/GC/2012/003. All indicators are expressed with a positive normative judgement, meaning that the higher the value, the better the active ageing outcome. Indicators are first aggregated within each domain. The overall value of the $A A I$ results from a weighted aggregation of the domain specific indices (Zaidi, et al., 2012) while it was decided to use weights recommended by the Expert Group (Table 2).

Table 2: Weights assigned to individual indicators and domains sub-indices by Expert group for weighting (UNECE methodology).

\begin{tabular}{|c|c|c|c|c|c|c|c|c|c|c|c|c|c|c|c|c|c|c|c|c|c|c|}
\hline $\begin{array}{l}\text { domain } \\
\text { (k) }\end{array}$ & \multicolumn{4}{|c|}{$\mathrm{E}$} & \multicolumn{4}{|c|}{$\mathrm{P}$} & \multicolumn{8}{|c|}{$\mathrm{L}$} & \multicolumn{6}{|c|}{$\mathrm{C}$} \\
\hline$(W)$ & \multicolumn{4}{|c|}{0,35} & \multicolumn{4}{|c|}{0,35} & \multicolumn{8}{|c|}{0,1} & \multicolumn{6}{|c|}{0,2} \\
\hline $\begin{array}{l}\text { indicato } \\
(j) \mathrm{r}\end{array}$ & E1 & E2 & E3 & E4 & P1 & $\mathrm{P} 2$ & P3 & P4 & L1 & L2 & L3 & L4 & L5 & L6 & L7 & L8 & $\mathrm{C} 1$ & $\mathrm{C} 2$ & $\mathrm{C} 3$ & $\mathrm{C} 4$ & $\mathrm{C} 5$ & C6 \\
\hline $\begin{array}{l}\text { indicator } \\
\text { weights }\end{array}$ & 0,25 & 0,25 & 0,25 & 0,25 & 0,25 & 0,25 & 0,3 & 0,2 & 0,1 & 0,2 & 0,2 & 0,1 & 0,1 & 0,1 & 0,1 & 0,1 & 0,33 & 0,23 & 0,17 & 0,07 & 0,13 & 0,07 \\
\hline
\end{tabular}

Source: Active Ageing Index 2012 for 27 EU Member States, 2012.

2014 national data, experts' weights and weighted sum model expressed final results of $A A I$ values for 28 European countries. Values were compared and the rank of countries was added.

The above mentioned UNECE methodology is one of approaches for $A A I$ construction while the results are influenced by aggregation method and weights adjustment. The aim of the paper is to compare the rank of the countries based on the "official" $A A I$ results with those which are explained in both 3.2. and 3.3. chapters.

Using of different weighing methods (RO, DR, PC and AHP exact methods) and various MCDA methods for the construction of individual sub-indices brought a lot of results in each domain. On the base of them were calculated domain's ranks of countries. The illustration of the range of results for the second domain (Participation in society) is given in the Table 3 . The similar situation as to the variety of results can be found in other three domains.

The indicators for each country in all four domains using the concrete weights and MCDA method were aggregated into the composite indicator, the countries were compared and their rank was added. As four weighting methods and four MSDA methods were used, 16 various ranks of countries were got. Minimum, maximum and mean rank of each country were computed and these statistics were compared with the overall $A A I$ computed by the UNECE methodology. All results are graphically displayed in the Figure 1, countries are sorted by the order of mean rank ascending.

The best position has Sweden using both methodologies: UNECE and the mean rank of all weighting and MCDA methods. Then follows Ireland, United Kingdom, Netherlands, Finland, Denmark but their position in the ranking is quite different in the comparison to UNECE methodology. At the end of the ranking of countries is Slovakia with the worst ranked active ageing of population. For situation in Slovakia are typical low employment rates in oldest age categories, their low participation in voluntary activities, lifelong learning, the political 
participation, use of ICT and mental well-being but high proportion of unpaid work in the area of childcare or adult care (see also Kaščáková, Kubišová, Nedelová, 2015)

Table 3: 2nd domain: Participation in society. Comparison of ranks of countries after using different weighting and MCDA methods.

\begin{tabular}{|c|c|c|c|c|c|c|c|c|c|c|c|c|c|c|c|c|}
\hline & \multicolumn{4}{|c|}{ Rank order standardization } & \multicolumn{4}{|c|}{ Scoring standardization } & \multicolumn{4}{|c|}{ Normalization } & \multicolumn{4}{|c|}{ Distance from ideal object } \\
\hline & RO & $\mathrm{DR}$ & $\mathrm{PC}$ & ESM & RO & $\mathrm{DR}$ & $\mathrm{PC}$ & ESM & RO & $\mathrm{DR}$ & $\mathrm{PC}$ & ESM & RO & $\mathrm{DR}$ & $\mathrm{PC}$ & ESM \\
\hline Belgium & 12 & 12 & 12 & 12 & 13 & 13 & 12 & 13 & 13 & 13 & 12 & 13 & 12 & 12 & 11 & 12 \\
\hline Bulgaria & 28 & 28 & 28 & 28 & 28 & 28 & 28 & 28 & 28 & 28 & 28 & 28 & 28 & 28 & 28 & 28 \\
\hline Czech Republic & 13 & 13 & 14 & 13 & 12 & 12 & 13 & 12 & 12 & 12 & 13 & 12 & 13 & 13 & 14 & 13 \\
\hline Denmark & 2 & 2 & 2 & 2 & 1 & 1 & 2 & 1 & 1 & 1 & 1 & 1 & 1 & 1 & 3 & 1 \\
\hline Germany & 11 & 11 & 11 & 11 & 8 & 8 & 9 & 8 & 9 & 9 & 10 & 9 & 10 & 10 & 10 & 10 \\
\hline Estonia & 17 & 17 & 17 & 17 & 19 & 19 & 19 & 19 & 18 & 18 & 19 & 18 & 17 & 17 & 16 & 17 \\
\hline Ireland & 6 & 6 & 6 & 6 & 9 & 9 & 7 & 9 & 7 & 7 & 7 & 7 & 8 & 8 & 7 & 8 \\
\hline Greece & 24 & 24 & 24 & 24 & 24 & 24 & 24 & 24 & 24 & 24 & 24 & 24 & 24 & 24 & 24 & 24 \\
\hline Spain & 15 & 15 & 15 & 15 & 14 & 14 & 14 & 14 & 14 & 14 & 15 & 14 & 15 & 15 & 15 & 15 \\
\hline France & 7 & 7 & 7 & 7 & 5 & 5 & 6 & 5 & 6 & 6 & 6 & 6 & 7 & 7 & 6 & 7 \\
\hline Italy & 21 & 21 & 21 & 21 & 15 & 15 & 15 & 15 & 16 & 16 & 16 & 16 & 16 & 16 & 17 & 16 \\
\hline Cyprus & 21 & 21 & 18 & 20 & 22 & 22 & 21 & 22 & 22 & 22 & 20 & 22 & 21 & 21 & 19 & 21 \\
\hline Latvia & 26 & 26 & 26 & 26 & 27 & 27 & 27 & 27 & 27 & 27 & 27 & 27 & 27 & 27 & 26 & 27 \\
\hline Lithuania & 16 & 16 & 16 & 16 & 18 & 18 & 17 & 18 & 19 & 19 & 18 & 19 & 20 & 20 & 18 & 20 \\
\hline Luxembourg & 3 & 3 & 3 & 3 & 6 & 6 & 5 & 6 & 5 & 5 & 5 & 5 & 5 & 5 & 5 & 5 \\
\hline Hungary & 19 & 19 & 20 & 19 & 16 & 16 & 16 & 16 & 17 & 17 & 17 & 17 & 18 & 18 & 20 & 18 \\
\hline Malta & 14 & 14 & 13 & 14 & 17 & 17 & 18 & 17 & 15 & 15 & 14 & 15 & 14 & 14 & 13 & 14 \\
\hline Netherlands & 1 & 1 & 1 & 1 & 2 & 2 & 1 & 2 & 2 & 2 & 4 & 2 & 4 & 4 & 4 & 4 \\
\hline Austria & 8 & 8 & 8 & 8 & 10 & 10 & 10 & 10 & 10 & 10 & 9 & 10 & 9 & 9 & 9 & 9 \\
\hline Poland & 25 & 25 & 25 & 25 & 25 & 25 & 25 & 25 & 25 & 25 & 25 & 25 & 25 & 25 & 25 & 25 \\
\hline Portugal & 21 & 21 & 22 & 22 & 21 & 21 & 22 & 21 & 21 & 21 & 22 & 21 & 19 & 19 & 21 & 19 \\
\hline Romania & 27 & 27 & 27 & 27 & 26 & 26 & 26 & 26 & 26 & 26 & 26 & 26 & 26 & 26 & 27 & 26 \\
\hline Slovenia & 9 & 9 & 10 & 9 & 11 & 11 & 11 & 11 & 11 & 11 & 11 & 11 & 11 & 11 & 12 & 11 \\
\hline Slovakia & 23 & 23 & 23 & 23 & 23 & 23 & 23 & 23 & 23 & 23 & 23 & 23 & 23 & 23 & 23 & 23 \\
\hline Finland & 4 & 4 & 4 & 4 & 4 & 4 & 3 & 4 & 4 & 4 & 2 & 4 & 3 & 3 & 2 & 3 \\
\hline Sweden & 5 & 5 & 5 & 5 & 3 & 3 & 4 & 3 & 3 & 3 & 3 & 3 & 2 & 2 & 1 & 2 \\
\hline United Kingdom & 10 & 10 & 9 & 10 & 7 & 7 & 8 & 7 & 8 & 8 & 8 & 8 & 6 & 6 & 8 & 6 \\
\hline Croatia & 18 & 18 & 19 & 18 & 20 & 20 & 20 & 20 & 20 & 20 & 21 & 20 & 22 & 22 & 22 & 22 \\
\hline
\end{tabular}

Source: the authors' work.

\section{Conclusion}

Different multi-criteria methods and methods for weights determination were used in the process of the composite index construction. These methods have led to different outcomes of ranking the countries. It is difficult to suppose which one method is the best for the construction of composite index. Some of them transform original values in the process of building both the domain indices and composite index and that is why the results could not be compared. What can be compared is the rank of country. The final ranks as a result of using 16 combinations of MSDA and weighting methods were averaged and the mean rank allowed us to compute the standard deviation $\left(s_{x}\right)$ as the variability measure of results of the particular method. The closest results to the mean rank had the normalization method with RO method for weights determination ( $s_{x}=0.81$ ). The mean difference between the mean rank position of the country and its rank in UNECE methodology is 1.86 . As each method has its own benefits 
and disadvantages, the recommendation for construction of composite index could be to use more methods and to average the results. This procedure can eliminate the specifics of some individual weighting or MSDA methods or subjectivity of weights choice.

Figure 2: Ranking of countries by the value of overall AAI as results of using different weighting and MCDA methods.

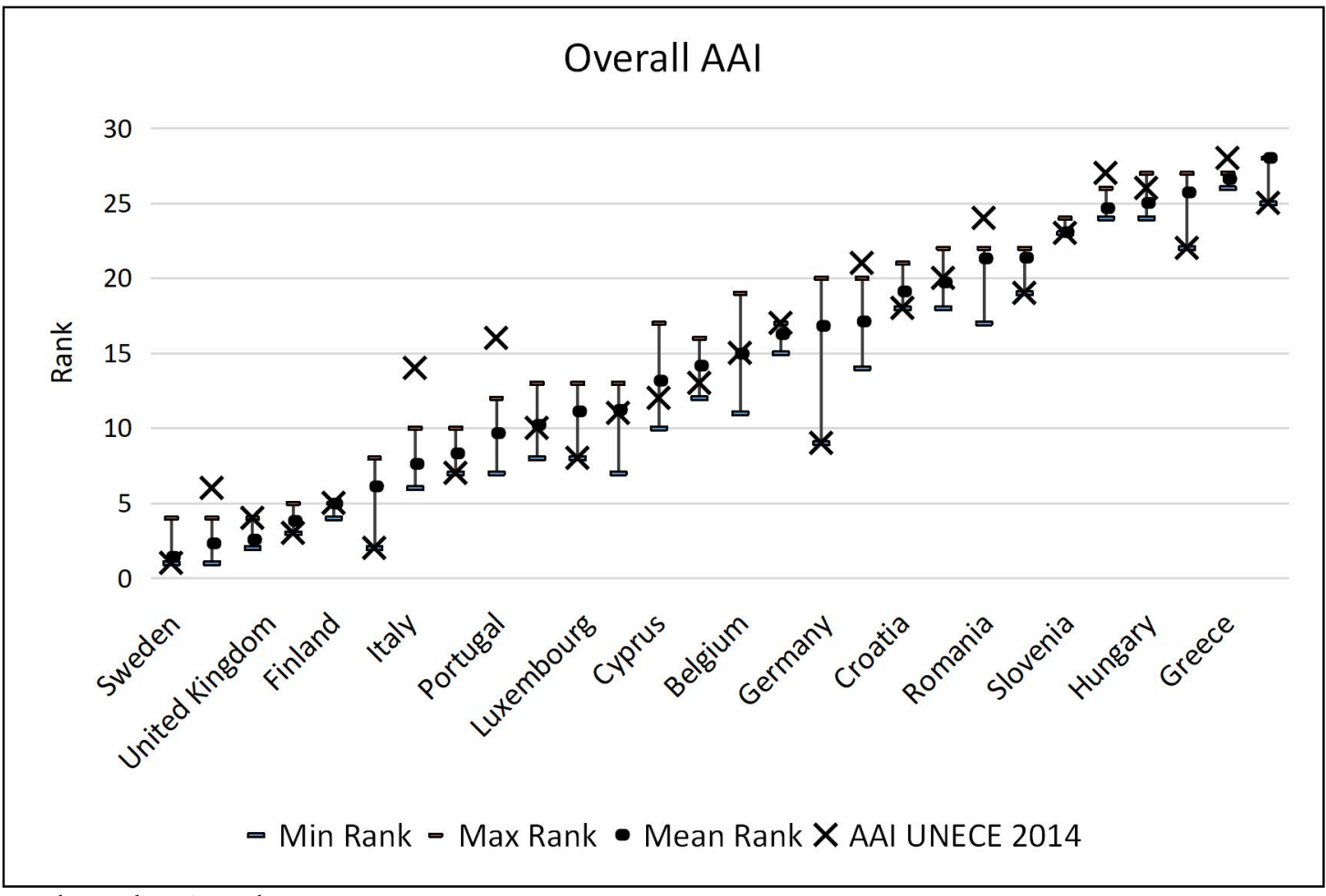

Source: the authors' work.

\section{Acknowledgements}

The support of the grant scheme VEGA 1/0621/17 is gladly acknowledged.

\section{References}

[1] Active Ageing Index. AAI in brief. 2012. http://www1.unece.org/stat/platform/display/AAI/I.+AAI+in+brief

[2] AHN, B. S., PARK, K. S. 2008, Comparing methods for multiattribute decision-making with ordinal weights. In Computers \& Operations Research, 2008, vol. 35, iss. 5, pp. 1660-1670.

[3] BOTTOMLEY, P. A., DOYLE, J. R. 2001. A comparison of three weight elicitation methods: good, better, and best. In Omega, 2001, vol. 29, iss. 6, pp. 553-560.

[4] KAŠČÁKOVÁ, A., KUBIŠOVÁ, L', NEDELOVÁ, G. 2015. Social and economic situation of silver generation in Slovakia. In 18th AMSE Applications of mathematics and statistics in economics. Prague: University of Economics, 2015. ISBN 978-80-245-20995.

[5] SAATY, T. L. 1980. Analytical hierarchy process: Planning, Priority Setting, Resource Allocation. New York: McGraw-Hill. 1980. ISBN-13: 978-0070543713.

[6] SIDORENKO, A., ZAIDI, A. 2013. Active ageing in CIS Countries: Semantics, challenges, and responses. In Current gerontology and geriatrics research, vol. 2013. 
[7] TZENG, G. H, CHEN, T. Y, WANG, J. C. 1998. A weight assessing method with habitual domains. In European Journal of Operational Research, 1998, vol. 110, iss. 2, pp. 342-367.

[8] ZAIDI, A., et al. 2012. Active Ageing Index 2012 for 27 EU Member States. Available at: http://www.euro.centre.org/data/1356002554_9393.pdf

[9] ZAIDI, A., et al. 2017. Measuring active and healthy ageing in Europe. In Journal of European Social Policy, 2017, volume. 27, iss. 2, pp. 138-157. ISSN 0958-9287.

[10] World Health Organization (WHO), 2002. Active ageing: a policy framework. Available at: http://www.who.int/ageing/publications/active_ageing/en/ . 
20th International Scientific Conference AMSE

Applications of Mathematics and Statistics in Economics 2017

Szklarska Poręba, Poland

30 August 2017 - 3 September 2017 